\title{
A social-democracia trabalhista: Marcello Alencar e a política no Rio de Janeiro
}

\author{
Marly Motta ${ }^{1}$
}

\begin{abstract}
Resumo
O objetivo deste trabalho é entender, a partir do depoimento do ex-governador Marcello Alencar aos pesquisadores do CPDOC-FGV, os limites e as possibilidades de implantação de um partido social-democrata "de massa" no Rio de Janeiro. Dentro de uma perspectiva mais ampla, a entrevista de Marcello fornece algumas pistas importantes para se compreender o fracasso desse projeto, que não conseguiu formar um eixo articulado de poder, capaz de se contrapor à tradicional hegemonia exercida pelo PMDB no espaço político carioca e fluminense.
\end{abstract}

Palavras-chave: social-democracia trabalhista; partidos políticos; socialismo moreno.

\begin{abstract}
This article intends to aprehend, with the help of the interview given by ancient governor Marcello Alencar to CPDOC-FGV's researchers, the limits and possibilities of a "mass" social-democratic party in Rio de Janeiro. In a larger perspective, Alencar's testimony offers important clues for us to understand the failure of such project, that was not able to form an articulate power axis capable of opposing to the traditional political leadership of PMDB in the city and the state of Rio de Janeiro.
\end{abstract}

Key words: labour social-democracy; political parties; "brunet" socialism.

Ninguém ganhava do Brizola no PDT, porque ele tinha botado a alma dele ali. Foi quando Covas me convenceu e fui para o PSDB, que também agregava os companheiros que tinham ido para o exílio, muitos setores de esquerda. A nossa social-democracia foi constituída ali. Até ficou um pouco de salto alto, porque pegou pessoas de nível mais universitário. E você tem que viver para se agregar a uma política. Brizola tinha essa vantagem, conhecia o sofrimento. Uma coisa é ser teórico (...); outra coisa é ter vivência (Marcello Alencar).

\footnotetext{
${ }^{1}$ Doutora em história (UFF), professora da FGV
} 
Perguntado sobre sua saída do PDT, partido do qual foi um dos fundadores junto com Leonel Brizola em 1980, e seu ingresso no PSDB 13 anos depois, levado pelas mãos do paulista Mário Covas, Marcello Alencar fez uma interessante comparação entre os dois partidos. ${ }^{2}$ Em sua resposta, o ex-governador fluminense (1995-1999) lançou mão de dois pares opostos para caracterizar, de um lado, a social-democracia de Fernando Henrique Cardoso, e de outro, o trabalhismo de Brizola. A primeira foi definida por meio de uma imagem exemplar - "salto alto" - usada para qualificar os "universitários" que, a exemplo de Fernando Henrique, teriam construído o modelo social-democrata no Brasil. Já o trabalhismo - de Vargas, Jango e Brizola - seria marcado, menos por uma racionalidade ligada ao conhecimento e ao saber, e mais por sentimentos de emoção, aqui representados por palavras como "sofrimento" e "alma". A esta oposição - "salto alto" x "sofrimento" -, Marcello conectou, até por decorrência, outra, que contraporia "teoria" a "vivência". Uma coisa era a "teoria" dos tucanos; outra, a "vivência" dos trabalhistas.

O objetivo deste trabalho é entender, a partir desse depoimento de Marcello Alencar aos pesquisadores do CPDOC-FGV, os limites e as possibilidades de implantação de um partido social-democrata "de massa" no Rio de Janeiro. A aposta político-partidária então feita visava incorporar a longa "vivência" do trabalhismo, especialmente na cidade do Rio de Janeiro, às "teorias" do tucanato, construídas sobretudo em cima da realidade socioeconômica de São Paulo. Dentro de uma perspectiva mais ampla, a entrevista de Marcello fornece algumas pistas importantes para se compreender o fracasso desse projeto que, como pretendo demonstrar, não conseguiu formar um eixo articulado de poder capaz de se contrapor à tradicional hegemonia exercida pelo PMDB no espaço político carioca e fluminense.

$\mathrm{O}$ artigo se estruturará em três partes. Na primeira analisarei que matrizes do trabalhismo foram reivindicadas por Marcello Alencar como fundamentais em sua formação. Em seguida, mostrarei os desafios por ele enfrentados, no afã de abrigar na mesma legenda partidária - o PSDB-RJ - eleitores de perfis diferentes, de classe média e de corte popular. Finalmente, investigarei as condições políticas que levaram ao

\footnotetext{
2 A entrevista, englobando um total de 22 horas, foi concedida aos pesquisadores Marly Motta e Carlos Eduardo Sarmento (CPDOC-FGV), entre novembro de 2005 e março de 2006, para compor a série Conversando sobre política, parte do projeto Memória política carioca e fluminense, resultado do convênio entre o CPDOC e a ALERJ.
} 
fracasso desse projeto: depois de Marcello, mais nenhum político do PSDB conseguiu se alçar ao Executivo carioca e fluminense. ${ }^{3}$

\section{Do trabalhismo ao socialismo moreno ${ }^{4}$}

Compartilhando com boa parte de sua geração - nasceu em 1925 - o encanto pelo ideário nacionalista, Marcello Alencar relaciona sua adesão ao universo da política como resultado da ação do "velho Horta Barbosa" na liderança da campanha pelo "petróleo é nosso". 5 A esse "nacionalismo", explicitamente identificado com a figura de Getulio Vargas, Marcello juntou uma outra matriz do chamado trabalhismo: a política de incorporação das massas populares, esta mais colada à atuação do ex-presidente João Goulart (1961-1963). Por isso mesmo fez questão de narrar um episódio que viveu na condição de procurador-geral do Instituto de Aposentadorias e Pensões dos Comerciários (IAPC) e que, a seu ver, retratava a "alma" do trabalhismo, profundamente marcado pelo "sofrimento dos desvalidos":

Ele [Goulart] recebeu a visita de um casal de índios com trigêmeos e, quando foi beijar as crianças, sentiu que estavam com febre. Aquilo o atormentou: "Convoca o Marcello, manda ele ver onde é que a gente pode internar essas crianças. Estão doentes!" Até eu ser contactado passou-se um tempo, e ele, de dez em dez minutos, perguntava: “Já está resolvendo o caso dos meninos?" Ele tinha uma atenção, um carinho pelas pessoas, impressionante. Era interessantíssimo nesse aspecto, um sujeito muito sensível, sentimental. ${ }^{6}$

Depois do golpe civil-militar de 1964, perdido o cargo de procurador, mas liberado da cassação a que muitos petebistas foram submetidos, Marcello Alencar abriu um escritório de advocacia, e se tornou um conhecido defensor de presos políticos. Sua primeira experiência eleitoral ocorreu em 1966, quando o MDB obteve uma estrondosa vitória nas eleições parlamentares na antiga Guanabara, estado criado em 1960 por

\footnotetext{
3 Para o governo do estado foram eleitos: Anthony Garotinho (PDT/PMDB); Rosinha Garotinho (PMDB); Sérgio Cabral (PMDB). Para a prefeitura da capital foram eleitos: César Maia (PFL); Eduardo Paes (PMDB).

${ }^{4}$ Sobre o trabalhismo, ver entre outros, a obra clássica de Ângela de Castro Gomes, A invenção do trabalhismo, São Paulo: Vértice; Rio de Janeiro: IUPERJ, 1988. Sobre o socialismo moreno, ver João Trajano Sento-Sé, Brizolismo: estetização da política e carisma, Rio de Janeiro, FGV, 1999.

5 O entrevistado refere-se ao general Horta Barbosa, primeiro presidente do Conselho Nacional do Petróleo (CNP), criado em 1938. Defensor do monopólio estatal do petróleo foi um dos principais incentivadores da campanha "O petróleo é nosso", que permitiu a criação da Petrobras em 1954.

${ }^{6}$ Entrevista com Marcello Alencar.
} 
ocasião da transferência da capital para Brasília. ${ }^{7}$ Marcello ocupou a suplência de Mário Martins no Senado até 1969, quando ambos foram cassados pelo AI-5, editado pela ditadura militar em dezembro do ano anterior.

A "vivência trabalhista", sobretudo aquela voltada para a inserção das massas na política, apareceu com frequência no depoimento de Marcello Alencar, especialmente para explicar a opção político-partidária pelo "partido do Brizola", como decorrência do fim do bipartidarismo e do surgimento de novos partidos no âmbito do processo de redemocratização deflagrado a partir do início dos anos 1980.

Quando Brizola escolheu o Rio de Janeiro como o lugar de sua volta à política, desejava, ao mesmo tempo, se beneficiar da posição privilegiada da cidade no cenário nacional e buscar no passado, especialmente na memória pré-64, os elementos que poderiam situá-lo favoravelmente no novo quadro político que se desenhava então. Brizola entendia ainda que o papel de "mártir da ditadura" só poderia lhe render benefícios políticos se acompanhado de um aparato político-institucional que canalizasse os anseios e as expectativas de amplos segmentos da população. Recebido o "bastão" do trabalhismo após a morte de Jango, o passo seguinte seria a retomada da sigla do PTB, que tivera uma grande força eleitoral na cidade do Rio de Janeiro entre 1945 e 1965.

Interpretações correntes atribuem a perda da sigla do PTB - o grupo da deputada Ivete Vargas (PTB-SP) acabou se apossando do partido, beneficiado por uma decisão do Tribunal Superior Eleitoral - à interferência política do general Golbery do Couto e Silva, chefe da Casa Civil do governo Figueiredo, que não veria com bons olhos a volta do trabalhismo sob a liderança de Brizola. No entanto, do ponto de vista de Brizola, pode-se entender também que a memória do pré-64, recuperada como plataforma necessária para seu relançamento político, não deveria se transformar em âncora, amarrando-o a tradições diretamente conectadas aos Vargas e a Jango. O desafio seria, sim, criar um novo partido que fosse, ao mesmo tempo, ponte com o passado e base de sustentação de projetos futuros.

Por isso mesmo, Brizola é recuperado por Marcello Alencar como uma nova matriz do trabalhismo - posteriormente chamada de socialismo moreno -, mais afinada com os anos 1980 e, portanto, com o debate de temas ligados a questões de gênero, raça, e direitos humanos. Comentando sobre a organização do PDT no Rio de Janeiro,

\footnotetext{
${ }^{7}$ O MDB-GB elegeu Mário Martins para o Senado; fez 15 das 21 cadeiras da Câmara dos Deputados e ocupou 40 das 55 vagas da Assembleia Legislativa.
} 
Marcello mostra a preocupação de Brizola com a cara que esse "novo partido trabalhista" deveria ter:

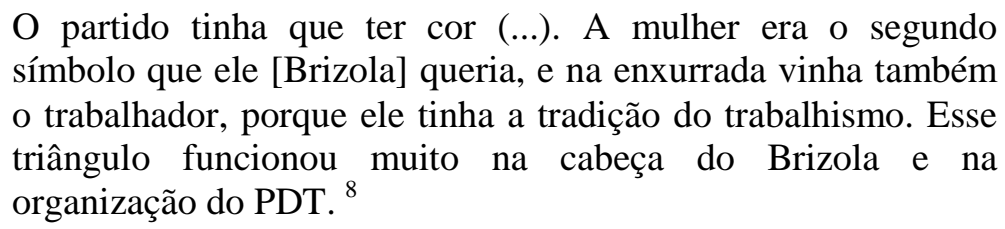

Quem se lembra dos pequenos cartazes colados em postes nas ruas dos subúrbios, anunciando a candidatura de Leonel Brizola ao governo do estado do Rio de Janeiro em 1982, lembra-se também da surpresa que foi o crescimento fulminante de seu nome nas pesquisas de voto. Foram arrasadores os números de sua vitória na cidade do Rio de Janeiro - $44 \%$ contra os $25 \%$ do candidato do governo federal, Moreira Franco -, em contraposição à derrota sofrida no antigo Estado do Rio para Miro Teixeira, apoiado pelo governador Chagas Freitas.

Componente do chamado socialismo moreno, o triângulo mulher-negrotrabalhador teria assim um peso importante na formação do governo Brizola. O secretariado, montado palmo a palmo, retratou bem a estratégia de ocupar espaços da administração pública com representantes do gênero feminino e da cor negra. Foi o caso de áreas diretamente conectadas com demandas sociais, como as secretarias do Trabalho e da Promoção Social, entregues, respectivamente, ao presidente do sindicato dos jornalistas, Carlos Alberto de Oliveira, e à advogada negra Idialeda do Nascimento. Ou ainda, da extinção da Secretaria de Segurança, tradicionalmente ocupada por um general indicado pelos órgãos de segurança, e sua substituição por dois órgãos: a Polícia Militar, cujo comando foi entregue a um coronel negro, Nazareth Cerqueira, e a Polícia Judiciária e de Direitos Civis, confiada ao promotor Luis Stockler.

\section{Liderança e chefia: algumas reflexões}

Presença atuante na estruturação e montagem do PDT, pessoa de confiança de Brizola, Marcello Alencar acreditava que seria escolhido para uma "missão política" no novo governo. Quem sabe a prefeitura da capital, que era então cargo de indicação do governador do estado. No entanto, interessado em conciliar os interesses dos dois principais braços do PDT - o trabalhista e o socialista -, Brizola indicou o médico Jamil Haddad, tradicional militante das hostes do antigo Partido Socialista Brasileiro. Para

\footnotetext{
${ }^{8}$ Entrevista com Marcello Alencar.
} 
Marcello Alencar, coube uma tarefa bem pouco familiar à sua experiência como advogado e militante trabalhista: a presidência do Banco do Estado do Rio de Janeiro (BANERJ). No entanto, o desgaste político-administrativo do prefeito indicado somouse à necessidade de um novo nome, com melhor trânsito no meio político. Em novembro de 1983, Marcello Alencar assumiu a prefeitura da cidade do Rio de Janeiro, onde permaneceria até $1^{\circ}$ de janeiro de 1986, quando deu posse ao prefeito eleito no ano anterior, Saturnino Braga.

A experiência de compartilhar o governo da cidade do Rio de Janeiro com o governador Brizola suscitou em Marcello Alencar algumas reflexões bem interessantes sobre o tipo de liderança/chefia que caracterizava o trabalhismo em geral e o do Rio de Janeiro em particular, sob o comando de Brizola. A primeira marca seria a figura do líder trabalhista, que encarnaria os ideais do trabalhismo, e cujo bastão deveria ser passado de geração em geração: Vargas-Jango-Brizola. Indagado se Brizola seria a escolha "natural" de Vargas para receber o bastão trabalhista, Marcello expõe a linha sucessória do trabalhismo que passaria antes por Jango, pelos laços pessoais mais profundos que mantivera com o chefe-maior:

Jango era um fazendeiro que ajudou o Dr. Getúlio a suportar o exílio de Itu the dando carinho. Jango era doce, era um homem agradável, era de ir todo dia à fazenda: "Dr. Getúlio, como vai o senhor?" E o Dr. Getúlio simpatizou muito com ele. Achava que Jango talvez representasse o espírito, as ideias do povo. Jango era um sujeito humilde, amigo dos peões. Adorava a peonada, gostava da conversa com gente simples. Já Brizola, era outra coisa. ${ }^{9}$

$\mathrm{Na}$ avaliação de Marcello, que "outra coisa" seria Brizola? Que tipo de liderança/chefia exercia no governo do Rio de Janeiro na condição de "dono do bastão do novo trabalhismo"? O poder centralizador de Brizola se mostrou com clareza na dificuldade que Marcello teve, durante a entrevista, de individualizar sua própria atuação nos anos em que esteve à frente da prefeitura do Rio de Janeiro. A afirmação, constantemente reiterada, de que Brizola lhe dera "total autonomia de atuação" era confrontada com a dificuldade de narrar o que fizera como prefeito do Rio. A figura de Brizola irrompia o tempo todo na narrativa, apesar dos nossos esforços como entrevistadores no intuito de forçá-lo a falar de si mesmo e de sua atuação políticoadministrativa. Brizola dominou a memória de Marcello ao se impor na forma como ele relembrou o passado.

\footnotetext{
${ }^{9}$ Entrevista com Marcello Alencar.
} 
Por isso mesmo, o relato do rompimento com Brizola é um dos pontos altos da entrevista de Marcello, onde fica mais evidente a tensão entre seu desejo de autonomia e a dependência em relação ao "chefe":

A divergência nasceu quando os jornais começaram a se referir ao "grupo marcelista". (...). Minha briga decisiva com Brizola se deu porque ele desconfiou de que eu estava querendo tomar o partido dele. Eu era um brizolista. Fazia até muitas concessões, porque achava necessário, para valorizá-lo (...). Minha briga com ele foi essencialmente porque ele não gostava de ver planta crescer, e eu cresci (...). Foi uma discussão dura. Naquele momento eu disse: "não fico mais no PDT, porque o PDT é do Brizola". Ele achava que eu estava ganhando as convenções do partido. Ora, se eu estava ganhando era porque estava sendo um prefeito eficiente (...). Não briguei com o partido, briguei com Brizola. Só que Brizola era o partido. No meu entender, o PDT é um partido que, comandado por outro, não vai dar certo. ${ }^{10}$

Foi com o apoio de Brizola, envolvido na preparação de sua própria campanha para as eleições presidenciais de 1989, que Marcello Alencar voltou à prefeitura do Rio de Janeiro (1989-1993), dessa vez montado em quase um milhão de votos (31,5\%), contra os 550 mil obtidos por Jorge Bittar do PT. Com um governo bem avaliado pelo eleitorado carioca, Marcello investiu na formação de um grupo político dentro do PDT capaz de viabilizá-lo como um eleitor privilegiado nas negociações com vistas à sua sucessão.

Em janeiro de 1992, já estavam na mesa, entre outros, os nomes da radialista Cidinha Campos, preferida de Brizola, e do engenheiro Luiz Paulo da Rocha, candidato indicado por Marcello Alencar desde setembro do ano anterior. O lançamento prévio feito pelo prefeito, sem o explícito beneplácito do governador, contrariou uma das regras básicas de convivência política dentro do PDT: a de que as iniciativas deveriam sempre partir de Brizola.

Ao contrário de outras eleições, em que o nome indicado por Brizola havia sido prontamente acatado dentro do partido - foi assim com Saturnino Braga, em 1985; com Darcy Ribeiro, em 1986; e com Marcello Alencar, em 1988 -, ele era agora afrontado pela disposição de Marcello, seu fraterno amigo e correligionário, de enfrentá-lo pelo controle das zonais cariocas do PDT. ${ }^{11}$ Usando as armas de um verdadeiro chefe partidário, em que as decisões são impostas de cima para baixo, e temendo o poder demonstrado pelo prefeito de organizar e arregimentar as bases, especialmente na Zona

\footnotetext{
${ }^{10}$ Entrevista com Marcello Alencar.

11 'Convenções dividem Brizola e Marcelo', Jornal do Brasil, 18/4/1992.
} 
Oeste, Brizola cancelou as convenções que indicariam os delegados à convenção estadual, designada para escolher o candidato do partido ao pleito municipal. O motivo alegado para essa intervenção foi a denúncia de que o candidato de Marcello teria oferecido emprego a delegados do PDT em troca de votos. ${ }^{12}$ Ainda em maio, Brizola manifestou explicitamente seu apoio a Cidinha, justificado não como uma "escolha pessoal", e sim como uma "manifestação da sociedade". ${ }^{13}$

Habituado a ter controle absoluto sobre as decisões do partido, Brizola se aborrecia com o que considerava perda de tempo e energia com as querelas da política local. Só que, ao insistir nessa postura tradicional de fazer do Rio uma ponte para a política nacional, desconsiderava uma pesquisa de opinião que o colocava bem atrás do prefeito em termos de avaliação dos respectivos governos: enquanto Marcelo ostentava $32 \%$ de aprovação e $23 \%$ de rejeição, o governador tinha $19 \%$ e $39 \%$, respectivamente. Esperando o bônus da vitória, Brizola acabou ficando com o ônus da derrota, já que outra "cria", César Maia (PMDB), conquistou aquele que seria o seu primeiro mandato à frente do Executivo carioca.

As eleições de 1992 provocaram transformações importantes no mapa político fluminense. Após dez anos de hegemonia, a Baixada Fluminense e a Zona Oeste da cidade do Rio, até então fortes redutos brizolistas, ligaram-se a outros políticos, como Marcello Alencar, que aí fizeram um pesado investimento em obras públicas e na formação de uma rede de cabos eleitorais, visando, sem dúvida, ao rico manancial de votos a ser explorado em ambas as regiões. ${ }^{14}$ Mesmo conhecendo os riscos de disputar um lugar ao sol, Marcello não queria continuar a ser uma estrela de segunda grandeza, dependente das decisões de Brizola, quase sempre guiadas pelo jogo da política nacional. Ao mesmo tempo, confiante na força de sua autoridade para dirimir as querelas locais, Brizola foi incapaz de barrar a formação do esquema marcellista, com o qual o então prefeito contava para chegar ao Palácio Guanabara em 1994.

Em março de 1993, foi consumada a saída de Marcello Alencar do PDT e seu ingresso no PSDB. O lançamento de sua candidatura ao governo do estado foi em grande estilo - uma festa em Bangu, com a presença do tucanato-mor, inclusive de

\footnotetext{
12 'PDT em crise cancela convenções no Rio', Jornal do Brasil, 23/5/1992.

13 'PDT quer que prefeito escolha o vice', Jornal do Brasil, 3/6/1992.

14 'Eleição redefine o poder político no estado; Baixada agora não é a mesma', Jornal do Brasil, 29/9/1992; 'Zona Oeste rompe com Brizola', Jornal do Brasil, 6/10/1992.
} 
Fernando Henrique Cardoso -, e pode ser considerado o pontapé inicial do projeto da social-democracia trabalhista no Rio de Janeiro.

\section{Do partido de massa a um partido de classe média}

A partida do projeto foi bem-sucedida: em 1994, Marcello Alencar, do PSDB, derrotou Anthony Garotinho, do PDT, no segundo turno, com uma vantagem de um milhão de votos. Ao ser indagado sobre o modo de conciliar tradições políticas diferentes - o trabalhismo e a social-democracia -, Marcello explica que precisou se "aggiornar":

As melhores cabeças do PMDB saíram e fizeram o PSDB. Aliás, a insistência nesse ponto foi uma coisa que sempre me preocupou. Eu dizia: "Não podemos ser um partido de salto alto..." (...). Eu tinha a conviç̧ão de que a social-democracia era uma feição nova do socialismo. Achava que eu, entrando no PSDB, iria me atualizar, me aggiornar, como aprendi com o papa João XXIII (...). ${ }^{15}$

No entanto, esse aggiornamento esbarrava em algumas questões que podem ser expressas, por exemplo, no uso recorrente da expressão "salto alto" para se referir ao aspecto "elitista" da social-democracia no Brasil. Daí a forte atuação política de Marcello no intuito de transferir para o PSDB fluminense a base eleitoral que o PDT e o "marcelismo" possuíam na Zona Oeste da cidade do Rio e na Baixada Fluminense, e que havia sido construída sobretudo durante seu segundo mandato na prefeitura carioca. É evidente o investimento que ele fez em líderes locais, de "salto baixo": Lucinha (Santa Cruz/Zona Oeste); Zito, de Caxias, colocado como presidente da Comissão de Finanças da ALERJ; Nelson Bornier, de Nova Iguaçu, feito secretário de Desenvolvimento da Baixada; Joca, de Belford Roxo; Simão Sessim, de Nilópolis, Cândido Matos, de São João de Meriti, entre outros. Um caso exemplar do tipo de aposta que Marcello fez em um perfil mais popular do PSDB fluminense foi o de Paulo Melo, elevado a líder do governo na ALERJ. Dono de seis mandatos de deputado estadual (1990-2010), agora no PMDB, Melo preside o Legislativo fluminense.

No entanto, como o próprio Marcello reconhece, ele tinha pouco tempo de casa para operar com desenvoltura esse PSDB vitaminado com políticos "de massa". A tensão vivida por ele entre a sua experiência trabalhista no PDT, de um lado, e o

\footnotetext{
${ }^{15}$ Entrevista com Marcello Alencar.
} 
exercício da liderança/chefia do PSDB, de outro, acabaria por definir os limites e as possibilidades de implantação da "social-democracia trabalhista" no Rio de Janeiro, como podemos sentir neste trecho de seu depoimento:

Minha ascensão foi muito rápida: eu me tornei governador, fui homenageado com a confiança do partido e me tornei chefe político sem ter tido nem o tempo nem a aflição do militante. Eu tinha pelo PSDB uma simpatia natural, traduzida por relações pessoais (...). Mas eu, por exemplo, tinha muito mais amigos no PDT (...). A verdade é que vim de um partido de massa para um partido cujo pensamento é considerado mais de classe média, mas que tinha lideranças de esquerda, de homens que foram cassados junto comigo, e isso influiu demais. Mas eu não conhecia a estrutura do PSDB, não sabia como o partido tinha sido organizado (...). Confesso que tudo isso contribuiu para eu não ter sido um bom organizador do partido nessa fase. Isso foi mascarado, porque eu ascendi ao poder, e o poder tem essa mancha: produz aproximações. ${ }^{16}$

Apesar de não se considerar um bom organizador do PSDB, Marcello, com base na natural "aproximação" que o poder sempre produz, ampliou sua base política para além da capital e da Baixada, por meio da adesão de muitos prefeitos do interior, bem como formou uma boa base parlamentar: em seu primeiro ano de mandato, o PSDB pulou de 16 para 22 deputados.

No entanto, pode ser creditado ao desconhecimento da estrutura do PSDB o fato de Marcello ter levado para o governo do estado a equipe de "técnicos" a ele ligados por laços pessoais, e que com ele haviam trabalhado na prefeitura carioca entre 1989 e 1992. Um deles foi o engenheiro Luiz Paulo Corrêa da Rocha, que Marcello colocou como seu vice, e que se mantém como uma das principais estrelas do PSDB fluminense. $^{17}$

Quer atraindo novos políticos para o PSDB, alguns deles oriundos de outros partidos, quer trazendo para postos-chave do governo antigos quadros da prefeitura carioca, Marcello relegou ao segundo plano os fundadores do PSDB fluminense, como por exemplo Ronaldo Cezar Coelho. Afinal, o bastão do tucanato estava em suas mãos, e uma das coisas que havia aprendido no trabalhismo era que o portador do bastão podia

\footnotetext{
${ }^{16}$ Entrevista com Marcello Alencar.

${ }^{17}$ Secretário de Obras na prefeitura de Marcello Alencar (1989-93), Luiz Paulo da Rocha foi eleito vicegovernador na chapa comandada por Marcello Alencar em 1994. Em 2001, exerceu o cargo de secretário dos Transportes na gestão do prefeito César Maia (2001-05). É deputado estadual desde 2003 pelo PSDBRJ. A entrevista de Luiz Paulo está disponível para consulta no Programa de História Oral do CPDOCFGV.
} 
tudo. Isso ficou claro em 1996, por ocasião da indicação da candidatura do PSDB à prefeitura do Rio:

\begin{abstract}
Ronaldo queria a qualquer custo ser candidato, achava que a vez era dele, que o candidato era ele. Eu não achava. E sou muito rígido nisso. Não apoio quem eu acho que não tem chance, porque isso é queimar a pessoa. Eu achava que o crescimento do Sérgio Cabral era muito mais expressivo, teria muito mais repercussão eleitoral (...). Ronaldo brigou, inclusive, na convenção do partido em Bonsucesso, saiu dizendo que tinham rasgado a camisa dele. Foi hostilizado. No fundo, quando você tem o comando, você o vê se refletir em horas assim: as pessoas ficam parciais, ficam do seu lado. E o meu candidato era o Sérgio [Cabral]. Isso sem necessidade de explicação, porque o próprio Ronaldo não veio a mim com a postulação. Ele achava que ser candidato era um direito dele. Tinha sido presidente do partido e quis fazer com que a candidatura dele fosse adotada. Houve a dúvida, e tirou-se a dúvida naquela reunião. Ele foi derrotado de uma maneira fragorosa. ${ }^{18}$
\end{abstract}

\title{
4. A derrota do projeto
}

Da mesma forma que em 1992 a derrota de Cidinha Campos, candidata de Brizola nas eleições para a prefeitura do Rio, sinalizou o início do declínio do brizolismo em seu principal reduto eleitoral, quatro anos depois, em 1996, a derrota de Sérgio Cabral (PSDB) para Luiz Paulo Conde, candidato do prefeito César Maia (PFL), indicou igualmente a perda do controle da capital fluminense para um forte competidor no campo político. César Maia não só conseguira se tornar o político mais identificado com a classe média carioca, tirando do PSDB um eleitorado potencial, como havia penetrado em regiões populares da cidade, principalmente por meio do projeto FavelaBairro, tomando de Marcello o contingente eleitoral que tradicionalmente votava no trabalhismo. Ao mesmo tempo, crescia no antigo Estado do Rio a força do PDT, agora identificado na figura de Garotinho, que logo demonstrou enorme capacidade de angariar prestígio e votos junto às massas populares fluminenses.

Embora não admita explicitamente, Marcello atribui o fracasso da socialdemocracia trabalhista no Rio de Janeiro, ou seja, da junção de duas tradições políticas diversas em um mesmo universo político-partidário, à aposta "errada" que fizera em Sérgio Cabral, então deputado estadual (PSDB), e que viria a ser governador fluminense a partir de 2007, pelo PMDB. Diferente de líderes tradicionais, como Ronaldo Cezar

\footnotetext{
${ }^{18}$ Entrevista com Marcello Alencar.
} 
Coelho, ou ainda de muitos dos recém-chegados ao ninho tucano, Cabral parecia unir um fácil acesso ao eleitorado popular - dos 11 mil votos em 1990, pulou para quase 170 mil em 1994 - a um trânsito igualmente fácil junto à classe média e à intelectualidade carioca. Essa é a principal justificativa de Marcello para o investimento que fez em Cabral, à custa, até mesmo, de passar por cima de figuras importantes do partido, como havia ocorrido nas eleições municipais de 1996.

[Sérgio] Foi escolhido presidente da Assembleia no meu governo. Quando perdeu a eleição para a prefeitura, em 96, veio me perguntar: "E agora?" Eu disse: "Agora você vai ser presidente da Assembleia outra vez" (...). A recondução dele foi garantida por mim. A gestão dele foi muito boa e leal para o meu governo, e eu o fortaleci. Ele e Paulo Melo eram soldados que comandavam o batalhão com eficiência e eu os prestigiava. Uma das formas de demonstrar esse prestígio era que, diante de muitas reivindicações de deputados, eu dizia: "Conversa primeiro com o Sérgio". ${ }^{19}$

Não por acaso, foi Cabral o primeiro nome em que Marcello pensou para a sua sucessão, quando, por motivo de saúde e devido aos baixos índices de aprovação popular, decidiu não disputar a reeleição. A recusa de Cabral em concorrer ao governo estadual em 1998, enfrentando César Maia e Garotinho, selou, em boa medida, a aspiração da seção fluminense do PSDB de alcançar o mesmo sucesso atingido em outros estados, especialmente São Paulo e Minas Gerais. Luiz Paulo da Rocha, um quadro técnico ligado a Marcello, foi o candidato do PSDB e ficou em terceiro lugar na disputa que elevou Garotinho ao patamar de liderança estadual, restringiu o espaço político de César Maia à cidade do Rio, e congelou o PSDB como força de segunda linha no quadro político fluminense.

Foi grande a hemorragia de quadros do PSDB para outros partidos, especialmente para o PMDB. É com amargura que Marcello narra a perda de seus dois “soldados”, Paulo Melo e Sérgio Cabral, para o PMDB:

[Sérgio] saiu do PSDB e esvaziou muito o partido. Àquela altura, ele tinha sido um deputado de 380 mil votos (...). Foi a pessoa em quem eu mais confiei. Tive a capacidade de entender que ele era o homem para o papel de comover as massas, que ele tinha uma presença política boa na rua, era capaz de improvisar (...). Joguei muito nele. Não fui feliz (...). [A saída do Sérgio] provocou o enfraquecimento [do PSDB]. Porque ele ainda tinha a situação de presidente da Assembleia. Tinha

\footnotetext{
${ }^{19}$ Entrevista com Marcello Alencar.
} 
condições de manter o controle da bancada. Tanto prefeito saiu do partido... Foi uma onda. ${ }^{20}$

Outro fator que contribuiu para o fracasso da social-democracia trabalhista no Rio de Janeiro foi a implantação da política econômica tucana, baseada no trinômio privatização/ajuste fiscal/enxugamento da máquina administrativa. Para um político de origem e de fé trabalhista, cuja matriz formadora se havia pautado pela tríade estatização/nacionalismo/expansão de gastos públicos, foi um constrangido acerto de contas com o passado ter que defender a privatização do BANERJ, das empresas públicas de transporte e de energia, entre outras:

Devo dizer que a privatização me criou muitos problemas interiores. Eu, um nacionalista mais do que convicto, vou ser governador e vou privatizar as empresas do Estado? Uma coisa me convenceu de que isso era necessário: a fragilidade do Estado na questão da eficiência e na questão financeira (...). Não perdi o sentido do nacionalismo, que para mim estava expresso na luta do petróleo, na defesa da Petrobras, de algumas empresas que realmente cumpriam o seu papel. Não perdi a noção político-ideológica. Eu era alguém que acreditava no Estado, achava que o Estado podia dar certo, que tudo dependia de um bom administrador que tivesse um ideal de serviço público. Mas confesso que me convenci de que as estruturas foram tornadas completamente ineficientes. ${ }^{21}$

A entrevista de Marcello Alencar permite, pois, perceber como as possibilidades de sucesso da social-democracia trabalhista no Rio de Janeiro foram limitadas. O constrangimento de ser "obrigado" no governo a adotar medidas de política econômica, que iam na direção contrária daquelas pregadas pelo trabalhismo de Vargas/Jango/Brizola, fragilizou o projeto do PSDB fluminense, que se mostrou, sobretudo, incapaz de produzir/reproduzir quadros políticos capazes de combinar a velha/renovada tradição trabalhista com a matriz social-democrata dos anos 1990.

\section{Referências Bibliográficas:}

Entrevista de Marcelo Alencar ao CPDOC (2005-2006)

Jornal do Brasil (1992)

GOMES, Ângela de Castro. A invenção do trabalhismo, São Paulo: Vértice; Rio de Janeiro: IUPERJ, 1988.

\footnotetext{
${ }^{20}$ Entrevista com Marcello Alencar.

${ }^{21}$ Entrevista com Marcello Alencar.
} 
MOTTA, Marly. O projeto político: a presidência da República. In: FERREIRA, Marieta de Moraes (org.). A força do povo: Brizola e o Rio de Janeiro. Rio de Janeiro:Alerj, CPDOC-FGV, 2008.

MOTTA, Marly. Rio de Janeiro versus Rio de Janeiro: o lugar da capital no cenário político fluminense. In: GOMES, Ângela de Castro Gomes (coord.). Direitos e cidadania: memória, política e cultura. Rio de Janeiro:Editora FGV, 2007.

SENTO-SÉ, João Trajano. Brizolismo: estetização da política e carisma, Rio de Janeiro, FGV, 1999. 